\title{
Drying Characteristics and Model of Chinese Hawthorn Using Microwave Coupled with Hot Air
}

\author{
Hai-Ming Yu, ${ }^{1,2}$ Chun-Cheng Zuo, ${ }^{1}$ and Qiu-Ju Xie ${ }^{3}$ \\ ${ }^{1}$ College of Mechanical Science and Engineering, Jilin University, Changchun 130022, China \\ ${ }^{2}$ College of Engineering, Heilongjiang Bayi Agricultural University, Daqing 163319, China \\ ${ }^{3}$ College of Information Technology, Heilongjiang Bayi Agricultural University, Daqing 163319, China
}

Correspondence should be addressed to Chun-Cheng Zuo; zuocc@jlu.edu.cn

Received 14 August 2014; Accepted 16 January 2015

Academic Editor: Oluwole Daniel Makinde

Copyright (C) 2015 Hai-Ming Yu et al. This is an open access article distributed under the Creative Commons Attribution License, which permits unrestricted use, distribution, and reproduction in any medium, provided the original work is properly cited.

\begin{abstract}
Microwave coupled with hot air drying kinetics and characteristics of hawthorn slices at different drying hot air temperatures, hot air velocities, and microwave power densities was investigated. The research results showed that drying occurred mainly in the falling rate period and in the accelerating period. Twelve mathematical models were selected to describe and compare the drying kinetics of hawthorn slices. By comparing three criterions including correlation coefficient, chi-square, and root mean square error, we determined that Weibull distribution model obtained the best fit and could best predict the experimental values. Consequently, Weibull distribution model could be used to aid dryer design and promote the efficiency of dryer operation by simulation and optimization of the drying processes. Moisture transfer from hawthorn slice was described by applying Fick's second law and the effective diffusivity values were calculated by simplified Fick's second law. The variable law of effective diffusivity values was consistent with the variable law of moisture ratio.
\end{abstract}

\section{Introduction}

Hawthorn is a kind of plant that belongs to hawthorn genus, which belongs to Rosaceae, is a unique fruit originated from China, and has 3000 years of cultural history. Currently, it mainly distributed in China, Europe, and North America [1]. Hawthorn can be made of many products, such as hawthorn cake, hawthorn juices, haw flakes, hawthorn jelly, and low sugar hawthorn candied. Hawthorn fruit is rich in vitamin C, flavonoids compounds, saponins, organic acids, polysaccharides, and other nutrients; it also contains a variety of minerals, with high nutritional value. Also, hawthorn has the function of digestion spleen, inflammation and cough, lower blood pressure, lower blood fat, increasing coronary blood flow, prevention of coronary heart disease, angina and cancer, and other antitumor efficiency of treatment. Therefore, varieties of hawthorn are widely used in pharmaceutical and food ingredients in China and Europe $[2,3]$. Moisture content of hawthorn is about $80 \%$ (w. b.), with crisp organic. So, it is vulnerable to mechanical damage in harvest and various processing after harvest, resulting in juice outflow, which provides a rich moisture and nutrients for microbacteria, and resulting in hawthorn rot, which bring enormous losses annually [4].

Drying is one of the widely used methods for postharvest preservation of fruit products. The basic objective in drying fruit products is the removal of water in the solids up to a certain level, at which microorganism and deterioration chemical reactions are greatly minimized [4-6]. In addition, dried food has longer shelf life in packages and lower transportation, handling, and storage costs [6]. Drying is a complicated process relating to simultaneous heat and mass transfer where water is transferred by diffusion from inside the fruit material to the air-fruit interface and from the interface to the air stream by convection $[7,8]$. The amount of energy required to dry fruit products depended on many factors, such as initial moisture and desired final moisture drying air temperature.

The dried slices of hawthorn fruits are much-loved hawthorn processed products; in addition to medical applications, it also can be made into drinks and raw or auxiliary 
material for other processed products. One of the main concerns of the commercial dried slices of hawthorn fruits is to obtain dried products of good quality. The quality of dried slices of hawthorn fruits can be affected by drying methods. Currently, there are mainly two kinds of drying methods including sun-drying and hot air drying for the slices of hawthorn fruits. Sun-drying is the most frequently used method for the slices of hawthorn fruits. This drying method is simple and there are no drying costs substantially, but drying takes a long time and the drying slices of hawthorn fruits are exposed to environmental contamination such as dust, rodents, birds, and microorganisms. Therefore, the quality of the dried products may be lowered significantly [4]. Hot air drying method has been widely applied because of simple structure, inexpensive drying equipment, and less being influenced by the external environment. But the thermal conductivity in hot air drying method is by the way of heat transfer from outside to inside. So, it has the defect of slow speed of heat transfer, long drying time, larger energy consumption, and serious damage to trace elements in hawthorn. This method seriously affects the quality of dried hawthorn $[9,10]$.

In recent years, the microwave drying technology is more widely applied. In microwave drying, microwave interaction with water molecules and internally generated heat throughout the drying of samples, which greatly reduces the drying time, improves energy efficiency and reduces the loss of trace elements in dried fruits. But there is a trouble of temperature uneven if it simply relies on the method of microwave heating, especially in the later stage of drying; the dried material is easy to cause gelatinization, which leads to poor quality of the dried product [11]. An effective measure to overcome some of the limitations of single microwave is to combine microwave with the vacuum or hot air drying technique [12]. Vacuum-microwave drying is a modern, efficient method of food, vegetable, fruit, and agricultural product preservation. It is a novel alternative method of drying that obtains products with acceptable quality. Compared with the hot air and microwave drying methods, vacuum-microwave drying permits shorter drying time and substantial improvement in the quality of dried products $[13,14]$. However, the vacuum-microwave drying equipment has limited commercial production because of high price, complex structure, high airtightness of the drying equipment, and operating difficulties in the drying process of products.

Microwave coupled with hot air (MCHA) drying is an innovative technique that dries the materials by microwave and hot air simultaneously and combines the advantages of microwave and hot air drying as well as overcomes the disadvantages associated with the application of each method alone [15]. The most important characteristic of microwave heating is volumetric heating. Drying materials could absorb microwave energy directly and internally and convert such energy into heat generated throughout the material by volumetric heating. At the same time, microwave energy promotes the movement of water from the interior of the drying products in the form of liquid or vapor toward the surface of the drying products. Thermal energy is conducted from the surface of the drying products toward the interior; water in the drying material is also removed from the surface toward the interior of the drying material while products are dried by hot air. Therefore, water removal from the drying material is commonly affected by microwave and hot air in MCHA drying. MCHA drying has faster heating rate and drying time than hot air drying or microwave drying alone [15-18].

Various mathematical models describing the drying characteristics of different fruits and vegetables had been proposed to optimize the drying process and design efficient dryers [19]. So far, there are more researchers that focus on hot air, microwave, and microwave vacuum drying technology for fruits and vegetables and get the corresponding drying characteristic curves and drying models, such as Guiné et al. [20], Gachovska et al. [21], Babalis et al. [22], Menges and Ertekin [7], Janjai et al. [23], Mihindukulasuriya and Jayasuriya [24], Alibas [25], Zhao et al. [26], Bai-Ngew et al. [27], Figiel [13], Nimmanpipug et al. [28], and Abano et al. [29]. There are fewer researchers that focus on microwave coupled with hot air drying technology for drying of fruits and vegetables, except for Varith [30], Alibas [31], and Gowen [17] researching on longan, soybeans, and pumpkin. However, the effects of dry factor on moisture ratio and drying rate of microwave coupled with hot air drying experiment were not researched systematically and the result analysis was not provided, and the mathematical models describing drying characteristics of microwave coupled with hot air drying technology were not presented in these studies listed above. Except for Unal and Sacilik [4] use the convective hot air drying technology for the drying characteristics of hawthorn; there was no research on the hawthorn drying moisture ratio, drying rate, and mathematical models using microwave coupled with hot air drying technology.

Therefore, the present study is conducted with the following objectives: (1) to dry the hawthorn slices in a microwave coupled with hot air dryer, and to determine the effect of hot air temperature, hot air velocity, and microwave power density on the dry characteristic, and to obtain drying characteristic curves; (2) to calculate the effective diffusivity of hawthorn slices samples; (3) to fit the experimental drying data obtained to drying models widely for predicting the drying characteristics of microwave coupled with hot air drying of hawthorn slices at different drying hot air temperature, hot air velocity, and microwave power density conditions.

\section{Materials and Methods}

2.1. Materials. North hawthorn is one of the main species among hawthorns cultured in Shandong, Hebei, Jilin, Henan, Liaoning, and Heilongjiang, China. Hawthorn used in experiment was cultured in Shandong, they were selected as the dried materials in December 2013. They were classified according to color, size, degree of mechanical damage, and decay after being bought. Those test samples of fresh color, the same size, no mechanical damage, and decay were packed into plastics bags in $0.5 \mathrm{~kg}$ lots after being washed and drained and stored in a refrigerator at $4^{\circ} \mathrm{C}$. The fresh hawthorns and the dried hawthorn slices were shown in Figure 1. The fresh hawthorn was put into a hot oven after being cut into slices with thickness of $5 \mathrm{~mm}$, which were continuously dried for 


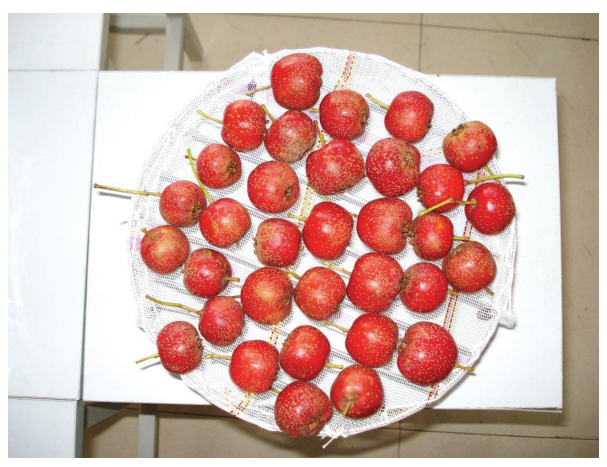

(a)

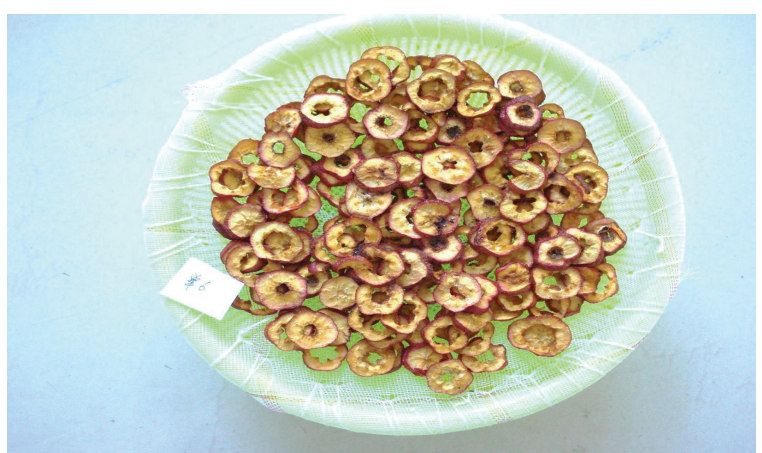

(b)

FIGURE 1: The appearances of hawthorn: (a) fresh hawthorn; (b) dry hawthorn slices.

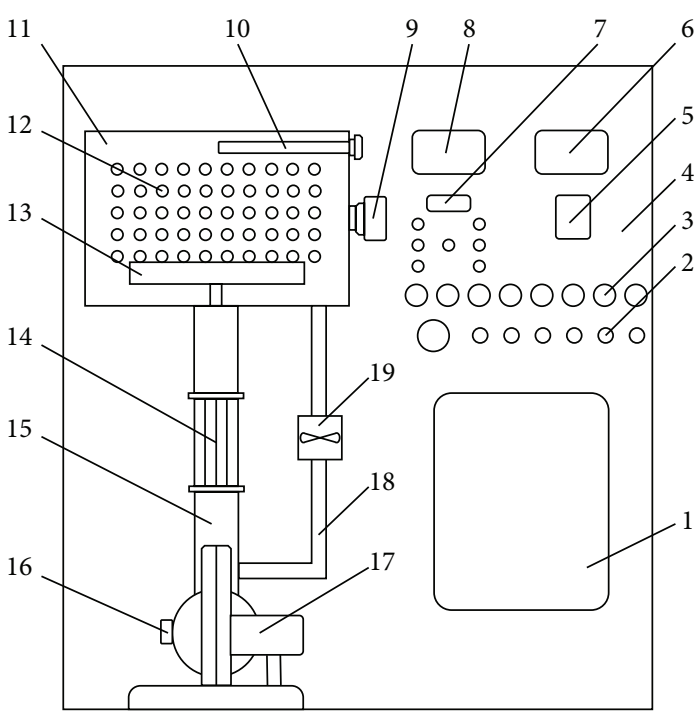

(a)

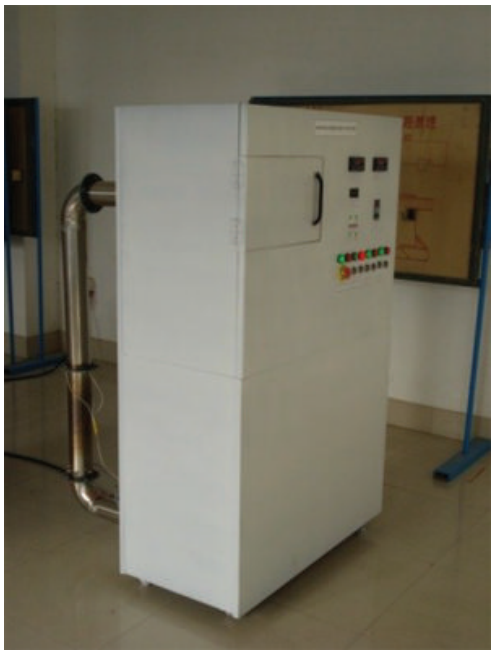

(b)

FIGURE 2: Photograph of experimental setup and schematic illustration of microwave coupled with hot air dryer. 1: Electric control part; 2: control buttons; 3: indicator; 4: control panel; 5: regulator; 6: temperature control device; 7: microwave control digital display; 8: air flow velocity indicator; 9: magnetron; 10: temperature sensor; 11: microwave cavity; 12: hot air distributor inlet; 13: rotating glass plate; 14: heater; 15: stainless steel inlet duct; 16: air flow velocity sensor; 17: centrifugal blower; 18: stainless steel air outlet duct; 19: axial fan.

12 hours with the hot air at the temperature of $70^{\circ} \mathrm{C}$. The moisture content of hawthorn slices was measured after this process. These experiments were replicated thrice to obtain a reasonable average. After drying, the sample was found to have a moisture content of about $77 \%$ (w. b.).

\subsection{Experimental Setup and Instrument}

\subsubsection{Microwave Coupled with Hot Air Dryer (MWCHAD).} The drying tests of hawthorn slicks were mainly completed by microwave coupled with hot air dryer (YHMW900100), which was manufactured at College of Engineering, Heilongjiang Bayi Agricultural University, Daqing, Heilongjiang. The schematic view and photograph of experimental setup were shown in Figure 2.

The size of the microwave coupled with hot air dryer was $1570 \times 1000 \times 505 \mathrm{~mm}$, which mainly consisted of microwave drying system and hot air drying system. Microwave drying system consisted of the magnetron, control systems, and microwave resonator cavity. The frequency of magnetron was
$2450 \mathrm{MHz}$, the microwave input power was $1300 \mathrm{~W}$, and the microwave output power was $900 \mathrm{~W}$. The control system was used to control the microwave power and the drying time, the microwave output power could be adjusted to $900,720,540$, 360 , and $180 \mathrm{~W}$, and the drying time could be controlled to the range of $0-180 \mathrm{~min}$. Microwave resonator cavity was made of 304 stainless steel and structural dimensions were of $330 \times$ $215 \times 350 \mathrm{~mm}$. Hot air drying system mainly consisted of air flow distributor, a heater, a control system, and a centrifugal fan powered of $550 \mathrm{~W}$. The air flow distributor was made of 304 stainless steel, structural dimensions were of $150 \times 150 \times$ $30 \mathrm{~mm}$, and the outlet was composed of 106 holes with $8 \mathrm{~mm}$ diameter. There was a row of $3 \mathrm{~mm}$ diameter holes on the side wall of the microwave cavity for discharging the wet air after drying. The heater consisted of three far-infrared carbon fiber heating tubes power of $800 \mathrm{~W}$ and stainless steel tube with diameter of $89 \mathrm{~mm}$. Control system consisted of a Pt100 temperature sensor with an accuracy of $\pm 0.5^{\circ} \mathrm{C}$ (HGB300, China), a frequency converter with an accuracy of $\pm 0.5 \%$ 
maximum air flow velocity (MT-B-0R7G-4-1010, the output frequency was $0-400 \mathrm{~Hz}$, China), an air flow velocity sensor with an accuracy of $\pm 0.2 \mathrm{~m} / \mathrm{s}+3 \% \mathrm{mv}$ (WD, range was 0 $30 \mathrm{~m} / \mathrm{s}$, China), and a digital display control instrument with an accuracy better than $\pm 0.5 \%$ FS (ch6, display range -19999999, China). The temperature sensor was installed in the upper part of the microwave cavity for the inside hot air temperature measurement; hot air temperature was controlled between $30^{\circ} \mathrm{C}$ and $100^{\circ} \mathrm{C}$ (dry bulb temperature). Since the normal operating temperature of the air flow velocity sensor is below $60^{\circ} \mathrm{C}$, to protect the air flow velocity sensor, it was installed at the outlet of the centrifugal blower to measure the air flow velocity. The air flow velocity was controlled between $0-5 \mathrm{~m} / \mathrm{s}$ inside microwave cavity. There was an interconnection between the microwave cavity of microwave drying system and distributor of hot air drying system, which can feed hot air uniformly into the microwave cavity.

2.2.2. Other Experimental Instrument. The moisture loss of test samples was weighed by a digital electronic balance (Model T1000, American Twin Brothers Co. Ltd., China) with the measurement range of $0-1000 \mathrm{~g}$ and an accuracy of $0.1 \mathrm{~g}$. The hawthorn initial moisture content was measured by a digital electronic balance (Model JA2003N, Shanghai Jingke Trade Co. Ltd., China) with the measurement range of 0 $210 \mathrm{~g}$ and an accuracy of $0.001 \mathrm{~g}$. A digital anemometer with an accuracy of \pm 0.1 dgts (Model MT826, Hong Kong Mattel Electronics Technology Co. Ltd., Hong Kong, China) was used to measure the air velocity.

2.3. Experimental Procedure. According to the china pharmacopoeia, thickness of dried hawthorn slices was $2 \sim 4 \mathrm{~mm}$; therefore, the thickness of fresh hawthorn slices used in each drying test was $5 \mathrm{~mm}$. According to the China pharmacopoeia, the dry experiment would be finished when moisture content of hawthorn slices was at $12 \%$ (w. b.). In most of the fruits and vegetables drying experiments, drying temperature was not more than $70^{\circ} \mathrm{C}$. It might affect the color and nutrients of fruit and vegetables if the temperature exceeded $70^{\circ} \mathrm{C}$, declining in the drying quality [32]. Therefore, the maximum hot air temperature is set to $70^{\circ} \mathrm{C}$.

It was necessary to run the hot air drying system for 10 to 20 min before the experiment; when the hot air temperature inside the microwave cavity reached the presetting temperature and stabilized, the fresh hawthorn slices on the plastic drying tray were put into the microwave cavity; a microwave drying system was started to dry. Drying experiments were carried out at different drying hot air temperatures of 50, 55, 60,65 , and $70^{\circ} \mathrm{C}$ and different hot air velocities of $1,1.5,2$, 2.5 , and $3 \mathrm{~m} / \mathrm{s}$ and different microwave power densities of 3 , $6,9,12$, and $15 \mathrm{w} / \mathrm{g}$. During the drying process, the weight of the dry sample was weighed once every $60 \mathrm{~s}$. The weight of the drying samples was weighted once every $10 \mathrm{~s}$ or $20 \mathrm{~s}$ when the moisture content of hawthorn slices was about $25 \%$ (w. b.). It did not impact the drying process since weighing was done within a few seconds [6]. Dried samples were put into the self-styled plastic bags after being allowed to cool down at an ambient temperature for $10 \mathrm{~min}$ and stored for the followup experiments.
2.4. Theoretical Approach and Mathematical Model. Moisture ratio of drying experiment expresses the residual moisture content (d. b.) of the material under certain conditions, the Moisture ratio is determined by the following $[25,33]$ :

$$
\mathrm{MR}=\frac{M_{t}-M_{e}}{M_{0}-M_{e}},
$$

where MR is moisture ratio (dimensionless), $M_{t}$ is the moisture content (d. b.) at $t\left(\mathrm{~kg}_{\text {water }} / \mathrm{kg}_{\text {dry solids }}\right), M_{e}$ is equilibrium moisture content (d. b.) $\left(\mathrm{kg}_{\text {water/dry solids }}\right)$, and $M_{0}$ is initial moisture content (d. b.) $\left(\mathrm{kg}_{\text {water/dry solids }}\right)$.

Hawthorn drying rate was an important parameter in the drying kinetics; in order to determine the relationship among hawthorn drying time, drying rate, and drying moisture content (d. b.), hawthorn slice drying rate was determined by the following $[25,33]$ :

$$
\mathrm{DR}=\frac{M_{t+\Delta t}-M_{t}}{\Delta t}
$$

where DR is drying rate $\left(\mathrm{kg}_{\text {water }} / \mathrm{min}^{\mathrm{kg}}\right.$ dry solids $), M_{t}$ and $M_{t+\Delta t}$ are the moisture content (d. b.) at $t$ and moisture content (d. b.) at $t+\Delta t\left(\mathrm{~kg}_{\text {water }} / \mathrm{kg}_{\text {dry solids }}\right)$, respectively, and $t$ is the drying time ( $\mathrm{min}$ ).

To further describe and forecast the moisture loss of hawthorn slices during the drying process of microwave coupled with hot air, 12 mathematical models (Table 1) were used to fit the hawthorn dried curves, and the optimal mathematical model was selected from models. In general, drying mathematical models were obtained by simplifying Fick's second law and considering the relationship between the average moisture content (d. b.) of dry material and drying time [34].

There were three evaluation criteria in determining the optimum drying mathematical model: the correlation coefficient $R^{2}$, chi-square value $\chi^{2}$, and root mean square error (RMSE) $[6,33]$. The correlation coefficient $R^{2}$ was used to indicate a close relationship among the variables. When the correlation coefficient $R^{2}$ was larger and closer to 1 , it indicated the more significant regression relationship. The values of $\chi^{2}$ and RMSE reflected the degree of variation between actual and expected value; its value was smaller and the prediction accuracy of the regression equation was higher. Therefore, the hawthorn dry optimal mathematical model should have a maximum value of $R^{2}$ and a minimum value of $\chi^{2}$ and RMSE. These statistics variables were calculated according to the following equation:

$$
\begin{gathered}
R^{2}=1-\frac{\sum_{i=1}^{N}\left(\mathrm{MR}_{\mathrm{exp}, i}-\mathrm{MR}_{\mathrm{pr}, i}\right)^{2}}{\sum_{i=1}^{N}\left(\overline{\mathrm{MR}}_{\mathrm{exp}}-\mathrm{MR}_{\mathrm{pre}, i}\right)^{2}}, \\
\chi^{2}=\frac{\sum_{i=1}^{N}\left(\mathrm{MR}_{\mathrm{exp}, i}-\mathrm{MR}_{\mathrm{pre}, i}\right)^{2}}{N-j}, \\
\text { RMSE }=\sqrt{\frac{\sum_{i=1}^{N}\left(\mathrm{MR}_{\mathrm{pre}, i}-\mathrm{MR}_{\mathrm{exp}, i}\right)^{2}}{N}},
\end{gathered}
$$


TABLE 1: Mathematical models for fitting of the moisture ratio values.

\begin{tabular}{lccc}
\hline Number & Model name & Model & Reference \\
\hline 1 & Newton & $\mathrm{MR}=\exp (-k t)$ & {$[42]$} \\
2 & Page & $\mathrm{MR}=\exp \left(-k t^{n}\right)$ & {$[35]$} \\
3 & Henderson and Pabis & $\mathrm{MR}=a \exp (-k t)$ & {$[43]$} \\
4 & Two term & $\mathrm{MR}=a \exp \left(k_{0} t\right)+b \exp \left(k_{1} t\right)$ & {$[44]$} \\
5 & Two-term exponential & $\mathrm{MR}=a \exp (-k t)+(1-a) \exp (-k a t)$ & {$[46]$} \\
6 & Verma et al. & $\mathrm{MR}=a \exp (-k t)+(1-a) \exp (-g t)$ & {$[47]$} \\
7 & Logarithmic & $\mathrm{MR}=a \exp (-k t)+c$ & {$[48]$} \\
8 & Wang and Singh & $\mathrm{MR}=1+a t+b t^{2}$ & {$[49]$} \\
9 & Approximation of diffusion & $\mathrm{MR}=a \exp (-k t)+(1-a) \exp (-k b t)$ & {$[24]$} \\
10 & Midilli et al. & $\mathrm{MR}=a \exp \left(-k t^{n}\right)+b t$ & $\mathrm{MR}=\exp \left(-(k t)^{n}\right)$ \\
11 & Modified page & $\mathrm{MR}=a-b \exp \left(-\left(k t^{n}\right)\right)$ & \\
12 & Weibull distribution & &
\end{tabular}

where $\mathrm{MR}_{\text {exp }, i}$ is the $i$ th moisture ratio value determined experimentally, $\mathrm{MR}_{\mathrm{exp}, i}$ is the $i$ th predicted moisture ratio value, $N$ is the number of observations, and $j$ is the number of drying constants.

2.5. Effective Moisture Diffusivity Coefficient. Effectivemoisture diffusion coefficient described moisture migration mechanism and reflected the important characteristics of drying model in the food and other materials drying process and was one of the essential parameters to calculate and simulate moisture migration mechanism of food and other materials. Effective moisture diffusion coefficient of hawthorn dried slices using microwave coupled with hot air could be calculated by simplifying Fick's second law. General series solution of this Fick's law written in spherical coordinates, with the assumptions of moisture migration being by diffusion, negligible shrinkage, constant diffusion coefficients, and temperature, was given as follows [35-37]:

$$
\begin{aligned}
\mathrm{MR} & =\frac{M_{t}-M_{e}}{M_{0}-M_{e}} \\
& =\frac{8}{\pi^{2}} \sum_{n=0}^{\infty} \frac{1}{(2 n+1)^{2}} \exp \left(-\frac{(2 n+1)^{2} \pi^{2} D_{\mathrm{eff}} t}{4 L^{2}}\right),
\end{aligned}
$$

where $D_{\text {eff }}$ is the effective diffusivity coefficient, $\mathrm{m}^{2} / \mathrm{s} ; L$ is the half-thickness of the samples, $m$; $n$ is the positive integer; and $t$ is the drying time, $s$.

For long drying periods, (4) could be further simplified to only the first term of the series. Thus, (4) was written as follows:

$$
\mathrm{MR}=\frac{M_{t}-M_{e}}{M_{0}-M_{e}}=\frac{8}{\pi^{2}} \exp \left(-\frac{\pi^{2} D_{\mathrm{eff}} t}{4 L^{2}}\right) .
$$

Equation (5) could be further expressed in a logarithmic form as follows:

$$
\operatorname{In}(\mathrm{MR})=\operatorname{In}\left(\frac{8}{\pi^{2}}\right)-\frac{\pi^{2} D_{\mathrm{eff}} t}{4 L^{2}} .
$$

TABLE 2: Uncertainties of the parameters during drying of hawthorn slices.

\begin{tabular}{lcc}
\hline Parameter & Unit & Comment \\
\hline Hot air distributor inlet temperature & ${ }^{\circ} \mathrm{C}$ & \pm 0.35 \\
Hot air distributor outlet temperature & ${ }^{\circ} \mathrm{C}$ & \pm 0.35 \\
Microwave cavity inlet temperature & ${ }^{\circ} \mathrm{C}$ & \pm 0.35 \\
Centrifugal blower outlet temperature & ${ }^{\circ} \mathrm{C}$ & \pm 0.35 \\
Ambient air temperature & ${ }^{\circ} \mathrm{C}$ & \pm 0.5 \\
Heater outlet temperature & ${ }^{\circ} \mathrm{C}$ & \pm 0.5 \\
Mass loss values & $\mathrm{min}$ & \pm 0.1 \\
Temperature value & $\mathrm{min}$ & \pm 0.1 \\
Uncertainty in the air velocity measurement & $\mathrm{m} / \mathrm{s}$ & 0.12 \\
Uncertainty in the hawthorn slices weight & $\mathrm{g}$ & 0.1 \\
measurement & & \\
Uncertainty in the initial moisture content & $\mathrm{g}$ & 0.001 \\
measurement of hawthorn slices & $\mathrm{g}$ & 0.1 \\
Uncertainty in the mass loss measurement & $\%$ & $\pm 0.1-0.2$ \\
Uncertainty in reading values of table $(\rho, \mathrm{cp})$. & $\%$
\end{tabular}

Hawthorn effective moisture diffusion coefficient could be calculated from the slope method, which was shown as follows:

$$
\text { Slope }=\frac{\operatorname{In}(\mathrm{MR})-\operatorname{In}\left(8 / \pi^{2}\right)}{t}=-\frac{\pi^{2} D_{\mathrm{eff}}}{4 L^{2}} .
$$

2.6. Experimental Uncertainty. Uncertainties and errors in experiments can arise from instrument selection, condition, calibration, environment, observation, reading, and test planning. In the drying experiments of hawthorn slices, the hot air temperatures, hot air velocity, dry sample weight, and weight losses were measured with appropriate instruments $[38,39]$. During the measurements of the parameters, the uncertainties that occurred are presented in Table 2.

\section{Results and Discussion}

3.1. Drying Moisture Ratio of Hawthorn Slices. The hawthorn moisture ratio curve varied with time, at different hot air 


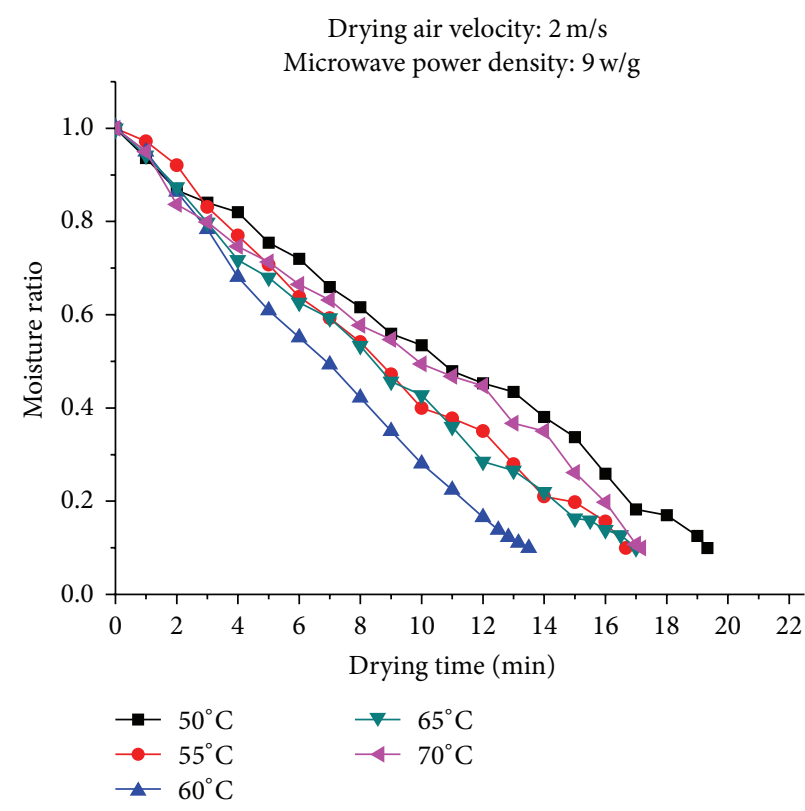

(a)

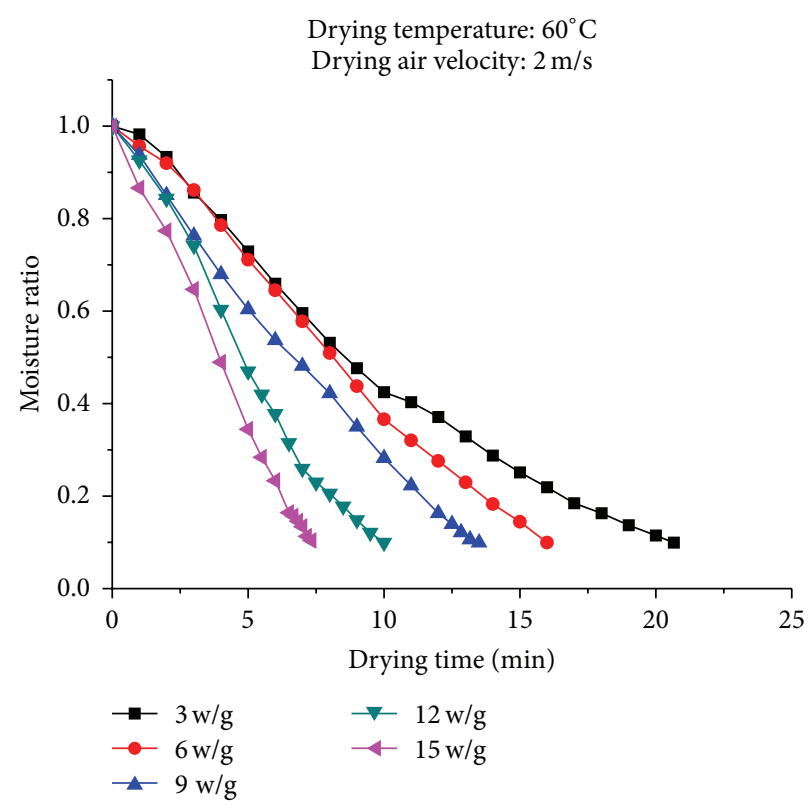

(b)

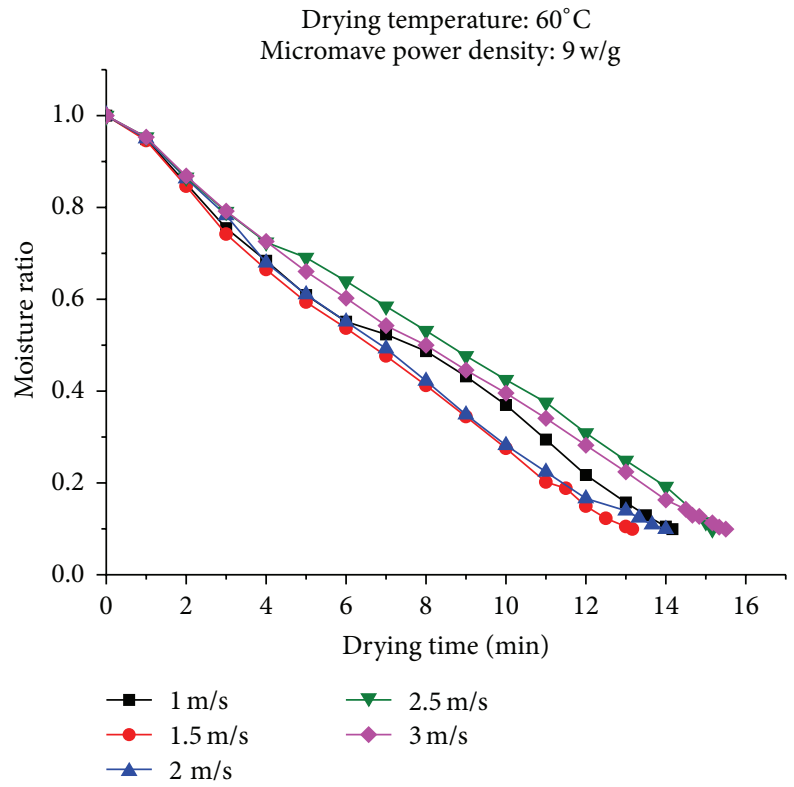

(c)

FIGURE 3: The experimental moisture ratios at different drying conditions: (a) experimental moisture ratios at different hot air temperatures; (b) experimental moisture ratios at different microwave power density; (c) the experimental moisture ratios at different drying hot air velocity.

temperatures, power density, and hot air velocity, which was shown in Figure 3. The range of the final moisture content of dried samples under different conditions was $12 \% \pm 0.5 \%(\mathrm{w}$. b.). It could be seen from Figure 3(a) that, under the condition of the drying hot air velocity of $2 \mathrm{~m} / \mathrm{s}$ and power density of $9 \mathrm{w} / \mathrm{g}$, when the drying temperature increased from $50^{\circ} \mathrm{C}$ to $70^{\circ} \mathrm{C}$, the drying time in which hawthorn slices reached a final moisture of $12 \%$ (w. b.) increased, with the increase of the temperature, and then decreased. When it reached $60^{\circ} \mathrm{C}$, drying time reached a minimum time of $13.5 \mathrm{~min}$. It was almost the same as the trends of the moisture ration curve at temperature of 55 and $65^{\circ} \mathrm{C}$. There was a greater change of the trends of the moisture ration curve at temperature of 50 , 60 , and $70^{\circ} \mathrm{C}$. For example, at temperature of 55 and $65^{\circ} \mathrm{C}$, the final drying time that reached moisture of $12 \%$ (w. b.) was 16.7 and $17 \mathrm{~min}$, while in 50,60 , and $70^{\circ} \mathrm{C}$, the drying time for reaching final moisture content of $12 \%$ (w. b.) was 19.3, 13.5, and $17.2 \mathrm{~min}$, respectively. The reason for time fluctuations and curve changing was that the drying of hawthorn slices was affected by microwave and hot air together. Microwave made hawthorn slices directly generate heat internally and hot air was to generate the convection heat transfer on 
the surface of the hawthorn slices. It could significantly shorten the drying time by using microwave coupled with hot air. The drying time was decided by microwave power rather than the temperature of the hot air [30]. When the hot air temperature was at $50 \sim 60^{\circ} \mathrm{C}$, the microwave drying played a decisive role and the drying time gradually decreased in the supporting role of hot air. When the hot air temperature was at $60 \sim 70^{\circ} \mathrm{C}$, the hot air drying played a decisive role, resulting in dry time gradually increasing [30]. As can be seen from Figure 3(b), when the drying temperature of $60^{\circ} \mathrm{C}$ and the drying hot air velocity of $2 \mathrm{~m} / \mathrm{s}$ remained unchanged, the density of the microwave power increased from $3 \mathrm{w} / \mathrm{g}$ to $15 \mathrm{w} / \mathrm{g}$, the drying time of hawthorn slices reaching a final moisture content of $12 \%$ (w. b.) would be reduced from 20.7 to $7.3 \mathrm{~min}$, and the trend of drying moisture ration curve varied greatly. The main reason that the drying time was reduced was the billions of rotation of polar water molecules per minute during the microwave heating, a lot of heat was generated because of the collision and friction between molecules, the water molecules absorbed the microwave power was increased after increasing the microwave power, the microwave drying gradually played a decisive role, resulting in a decline of the drying time [30]. As can be seen from Figure 3(c), when the drying conditions remained unchanged, which were the power density of $9 \mathrm{w} / \mathrm{g}$ and the drying temperature of $60^{\circ} \mathrm{C}$, the drying hot air velocity increased from $1 \mathrm{~m} / \mathrm{s}$ to $3 \mathrm{~m} / \mathrm{s}$ and the drying time of the hawthorn slices reaching a final moisture content of $12 \%$ (w. b.) varied with the increase of the velocity of hot air, which decreases after increasing. When the hot air velocity was $1.5 \mathrm{~m} / \mathrm{s}$, it has the shortest drying time of $13.2 \mathrm{~min}$. When the hot air velocity was $3 \mathrm{~m} / \mathrm{s}$, it has the longest drying time of $15.5 \mathrm{~min}$. In the drying of microwave coupled with the hot air, although hot air could accelerate the water evaporation of hawthorn slices surface and accelerate the velocity of drying, when the hot air velocity was too large, the temperature of the surface of hawthorn slices would be reduced and water evaporation would also be reduced, thus leading to the drying rate reducing and drying time increasing.

3.2. Drying Rate of Hawthorn Slices. Under the drying conditions with different temperatures, the power density, and hot air velocity, the curve of the drying rate of the hawthorn slices varying with moisture content (d. b.) was shown in Figure 4. It was apparent that the drying process involved four periods, accelerating period, falling period, another accelerating period, and another falling period, without a constant rate drying period. In all cases, at the early period of drying, the moisture content (d. b.) decreased and the drying rate began to increase and reached the first peak; with the further reduction of the moisture content (d. b.), the drying rate reached a minimum value; with further reduction of the moisture content (d. b.), drying rate experienced an another increase and reached the second peak, and drying rate began to decrease with decreasing of the reduction of moisture content (d. b.).

As can be seen from Figure 4, the drying process mainly occurred in the first accelerating period and the second falling period. The trends of the drying rate curve of hawthorn slices, in this paper, were consistent with which of soybean and apple slices using the method of microwave coupled with hot air drying reported in the literature 33 and 56. In the early drying stages of hawthorn slices, the initial increase of drying rate was believed to be caused by the "warming-up" of drying samples, when mass losses were small, the subsequent decrease in drying rate could be attributed to drying out of the hawthorn slices sample surface caused by evaporation of water. As can be seen from Figure 4(b), the size of the second peak in the drying curve generally increased as microwave power density was increased [17]. This might be related to an internal structure of the rapid formation of a porous, promoting the diffusion of water vapor by volumetric heating of the source. Driven by the microwave power, steam was forced through the hawthorn slices which expanded internal void structure. The appearance of the second peak in the drying curve might also be related to the changes of the dielectric loss factor of the hawthorn slices during drying [40].

\subsection{Mathematical Model of Hawthorn Slices Drying Curves.} Data of continuous moisture content (d. b.) obtained under conditions of different hot air temperature, microwave power density, and hot air velocity were converted into moisture ratio. They were fitted by 12 mathematical models with drying time as the independent variables. The mathematical models were shown in Table 1 . The three statistical values of the correlation coefficient $R^{2}$, the chi-square value of $\chi^{2}$, and the root mean square error (RMSE) obtained by nonlinear analysis under different drying conditions were shown in Table 3. As can be seen from the data in Table 3, Weibull distribution model has a maximum value of $R^{2}$ and minimum values of $\chi^{2}$ and RMSE. The variation range of these values was $0.98706 \sim 0.99961,0.0000444 \sim 0.00111$, and $0.00666 \sim 0.03336$, respectively. Therefore, the Weibull distribution model was considered the best model in the present study to represent the microwave coupled with hot air drying behavior of hawthorn fruits within the experimental range of study. It was shown as (8). Unal and Sacilik [4] studied a drying method of hot air convection for hawthorn drying kinetics, and they fitted five kinds of different drying mathematical models and drew a conclusion of Midilli et al. model fitting best. Probably, the drying methods and different drying characteristics at various drying conditions could contribute to the difference [37]:

$$
\mathrm{MR}=a-b \exp \left(-\left(k t^{n}\right)\right)
$$

where MR is the moisture ratio; $k$ is drying rate constant $\left(h^{-1}\right)$; $t$ is time $(h) ; a, n$, and $b$ is experimental constants.

The coefficient and constant values of the Weibull distribution model were obtained by using nonlinear regression procedure, after analyzing the Weibull distribution model according to the conditions of different drying air 


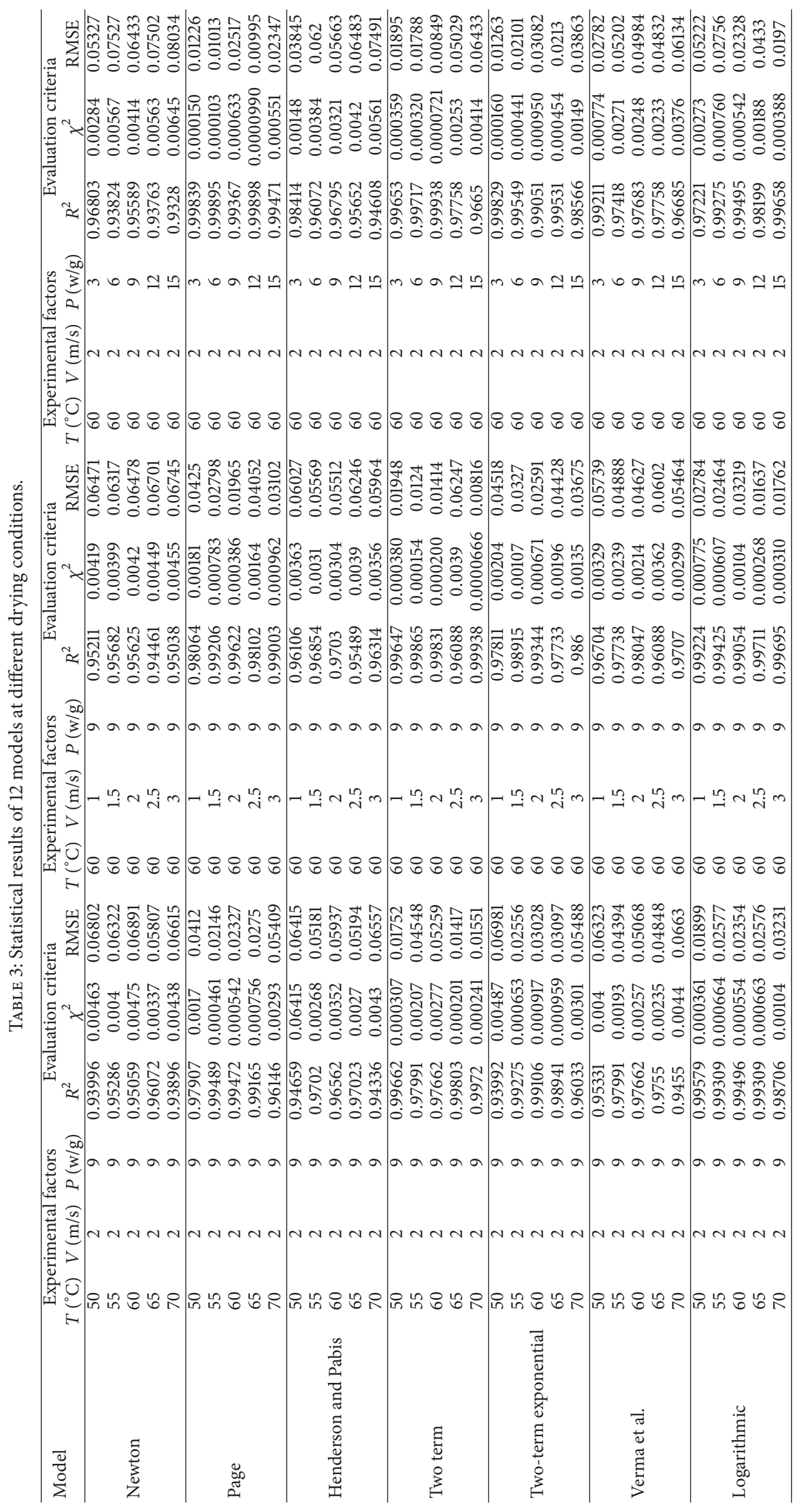




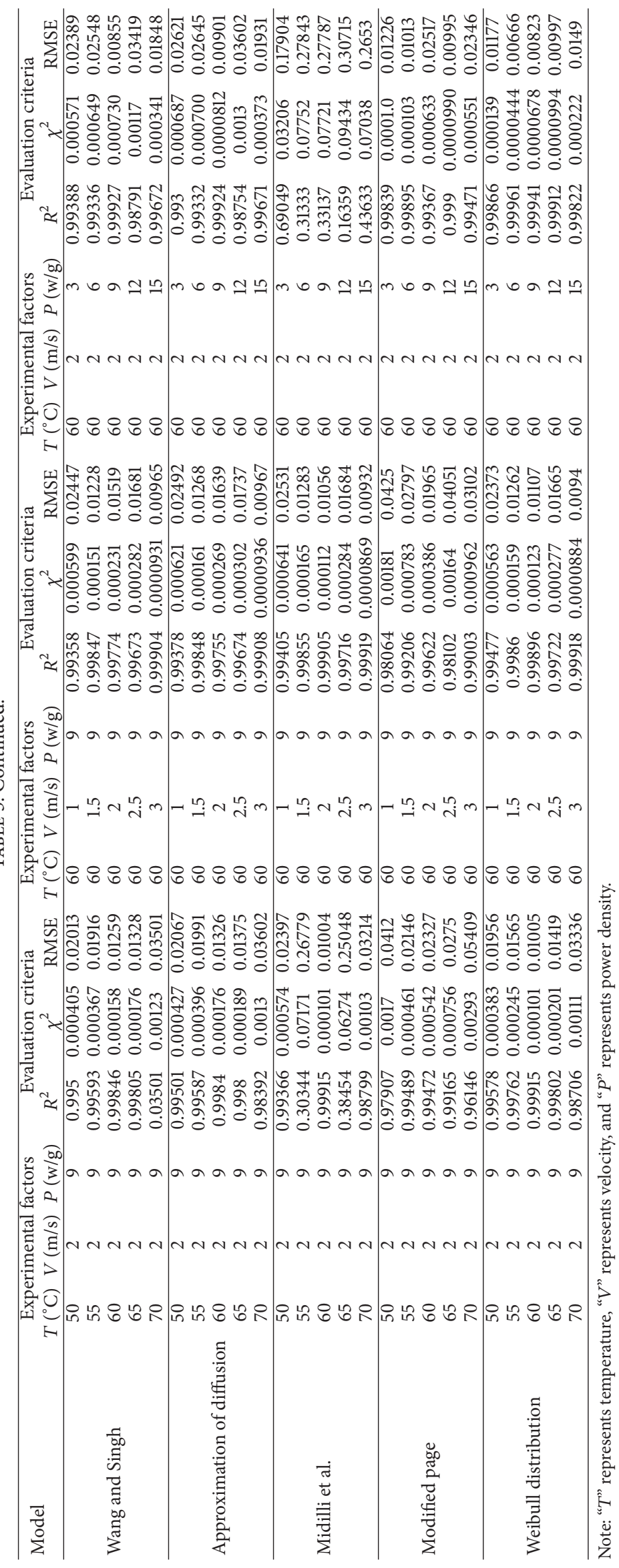




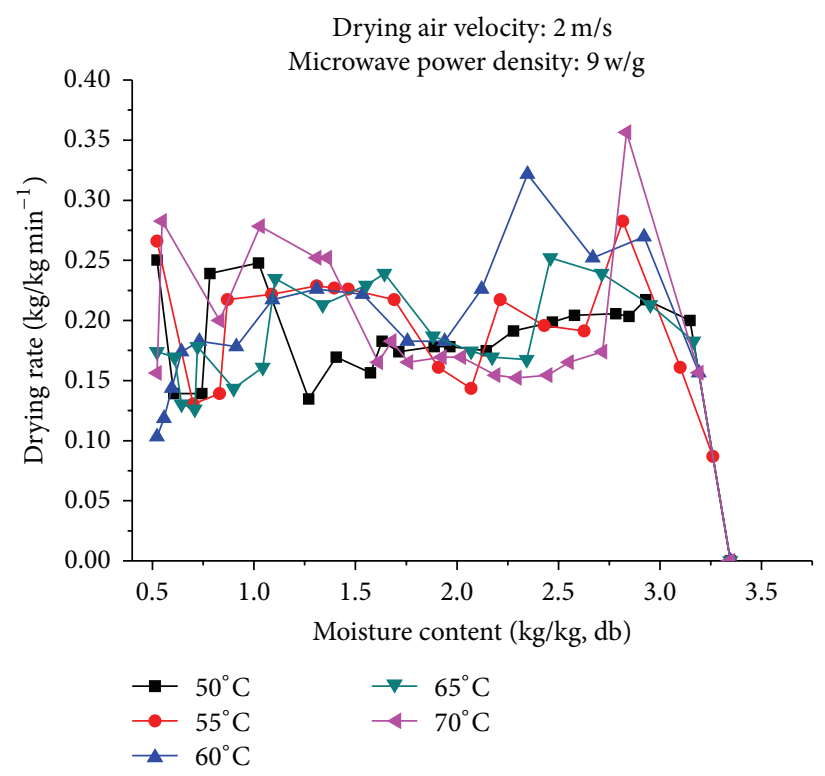

(a)

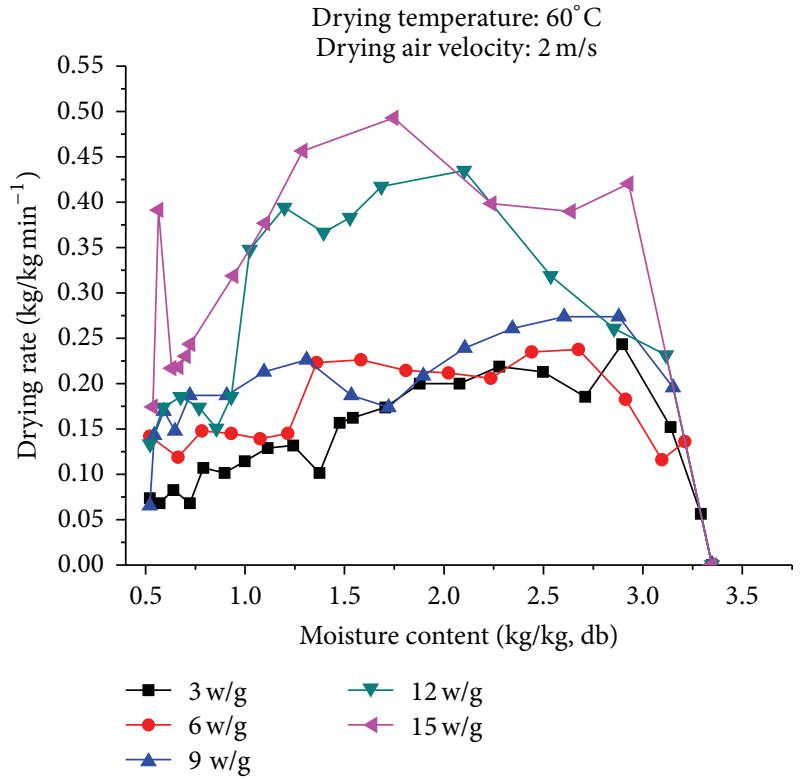

(b)

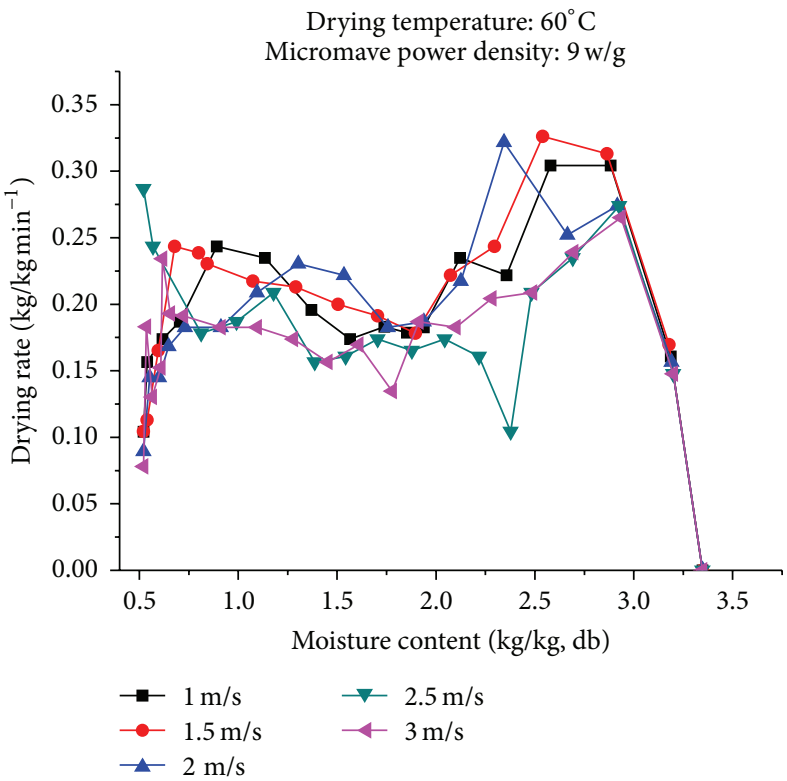

(c)

FIgURE 4: The experimental drying rate at different drying conditions: (a) experimental drying rate at different hot air temperatures; (b) experimental drying rate at different microwave power density; (c) experimental drying rate at different drying hot air velocity.

temperature, power density, and hot air velocity, which were shown in Table 4.

In order to further describe the influence of drying variables on Weibull distribution model, the relationship between the coefficients or constants $(a, b, k$, and $n)$ and the drying parameters (drying hot air temperature, power density, and hot air velocity) of the drying model were established based on regression analyzing method. Thus, the regression equations of these coefficients and constants against drying parameters for Weibull distribution model were as follows [35].
At hot air velocity of $2 \mathrm{~m} / \mathrm{s}$ and power density of $9 \mathrm{w} / \mathrm{g}$,

$$
\begin{array}{r}
a=153.257+7.5292 \times T+83.97412 \times T^{2} \\
-0.0006599 \times T^{3}, \quad\left(R^{2}=0.999909\right), \\
b=-150.272212+7.358245 \times T \\
-0.120352 \times T^{2}-0.00064991 \times T^{3}, \\
\left(R^{2}=0.97788\right),
\end{array}
$$


TABLE 4: Statistical results of Weibull distribution model and its constants and coefficients at different drying conditions.

\begin{tabular}{lccccccccc}
\hline $\begin{array}{l}\text { Power density } \\
(\mathrm{w} / \mathrm{g})\end{array}$ & $\begin{array}{c}\text { Hot air velocity } \\
(\mathrm{m} / \mathrm{s})\end{array}$ & $\begin{array}{c}\text { Hot air temperature } \\
\left({ }^{\circ} \mathrm{C}\right)\end{array}$ & \multicolumn{6}{c}{$\mathrm{MR}=a-b \exp \left(-\left(k t^{n}\right)\right)$} \\
\hline 9 & 2 & 50 & -1.035499 & -2.00178 & 0.014505 & 1.212663 & 0.99578 & 0.000383 & 0.01956 \\
9 & 2 & 55 & -0.497877 & -1.50544 & 0.03548 & 1.183477 & 0.99762 & 0.000245 & 0.01565 \\
9 & 2 & 60 & -0.650392 & -1.66494 & 0.041292 & 1.088001 & 0.99915 & 0.000101 & 0.01005 \\
9 & 2 & 65 & -0.998099 & -1.99287 & 0.03434 & 1.047371 & 0.99802 & 0.000201 & 0.01419 \\
9 & 2 & 70 & -1.046052 & -2.00178 & 0.017025 & 1.182729 & 0.98706 & 0.00111 & 0.03336 \\
9 & 1 & 60 & -234.5317 & -235.538 & 0.0003813 & 0.87117 & 0.99477 & 0.000563 & 0.02373 \\
9 & 1.5 & 60 & -1.327 & -2.33684 & 0.03812 & 0.99685 & 0.9986 & 0.000159 & 0.01262 \\
9 & 2 & 60 & -0.32725 & -1.33212 & 0.05019 & 1.1877 & 0.99896 & 0.000123 & 0.01107 \\
9 & 2.5 & 60 & -125.9629 & -126.957 & 0.000491 & 0.97128 & 0.99722 & 0.000277 & 0.01665 \\
9 & 3 & 60 & -5.48865 & -6.49861 & 0.01214 & 0.92148 & 0.99918 & 0.0000884 & 0.0094 \\
9 & 2 & 60 & -0.03587 & -1.05299 & 0.04139 & 1.27938 & 0.99866 & 0.000139 & 0.01177 \\
3 & 2 & 60 & -0.10307 & -1.09909 & 0.02695 & 1.48518 & 0.99961 & 0.0000444 & 0.00666 \\
6 & 2 & 60 & -0.9463 & -1.95202 & 0.04149 & 1.04665 & 0.99941 & 0.0000678 & 0.00823 \\
9 & 2 & 60 & 0.02062 & -0.96752 & 0.04765 & 1.71415 & 0.99912 & 0.0000994 & 0.00997 \\
12 & 2 & 60 & -0.38135 & -1.36752 & 0.0671 & 1.38279 & 0.99822 & 0.000222 & 0.0149 \\
15 & & & & & & & & & \\
9 & 2 & & & & & & & &
\end{tabular}

$$
\begin{array}{r}
k=-1.557235+0.064998 \times T \\
-0.00083127 \times T^{2}+0.0000035098 \times T^{3}, \\
\left(R^{2}=0.988926\right), \\
n=-28.792102+1.595119 \times T \\
-0.027976 \times T^{2}+0.0001615187 \times T^{3}, \\
\left(R^{2}=0.8852\right),
\end{array}
$$

at hot air temperature of $60^{\circ} \mathrm{C}$ and power density of $9 \mathrm{w} / \mathrm{g}$,

$$
\begin{aligned}
a= & -483.95564-886.38461 \times v \\
& +2063.75197 \times v^{2}-1106.06057 \times v^{3} \\
& +178.11714 \times v^{4}, \quad\left(R^{2}=1\right), \\
b= & -485.079-886.04951 \times v \\
& +2063.41156 \times v^{2}-1105.91771 \times v^{3} \\
& +178.09633 \times v^{4}, \quad\left(R^{2}=1\right), \\
k= & 0.78838-2.15232 \times v \\
& +2.04932 \times v^{2}-0.79114 \times v^{3} \\
& +0.10614 \times v^{4}, \quad\left(R^{2}=1\right), \\
n= & 7.93673-17.59687 \times v \\
& +15.34655 \times v^{2}-5.51279 \times v^{3} \\
& +0.69755 \times v^{4}, \quad\left(R^{2}=1\right),
\end{aligned}
$$

and at hot air temperature of $60^{\circ} \mathrm{C}$ and hot air velocity of $2 \mathrm{~m} / \mathrm{s}$,

$$
\begin{aligned}
a= & -9.0961+5.94968 \times W \\
& -1.26465 \times W^{2}+0.10493 \times W^{3} \\
& -0.00297 \times W^{4}, \quad\left(R^{2}=1\right), \\
b= & -10.32417+6.07773 \times W \\
& -1.28917 \times W^{2}+0.10685 \times W^{3} \\
& -0.00302 \times W^{4}, \quad\left(R^{2}=1\right), \\
k= & 0.1812-0.08313 \times W \\
& +0.01533 \times W^{2}-0.00114 \times W^{3} \\
& +3.03652 \times 10-5 \times W^{4}, \quad\left(R^{2}=1\right), \\
n= & -5.17636+4.13769 \times W \\
& -0.85497 \times W^{2}+0.0703 \times W^{3} \\
& -0.00198 \times W^{4}, \quad\left(R^{2}=1\right),
\end{aligned}
$$

where $T, v$, and $W$ are drying hot air temperature, drying hot air velocity, and power density, respectively.

In order to verify whether the Weibull distribution model could be well predicted to the characteristics of microwave coupled with hot air drying of hawthorn slices, (9) to (11) were substituted into the Weibull distribution model, and according to drying times of different drying conditions, the predictive values of MR based on the Weibull distribution model were obtained. The MR curve obtained from experiment and the MR curve based on the predicted values of 


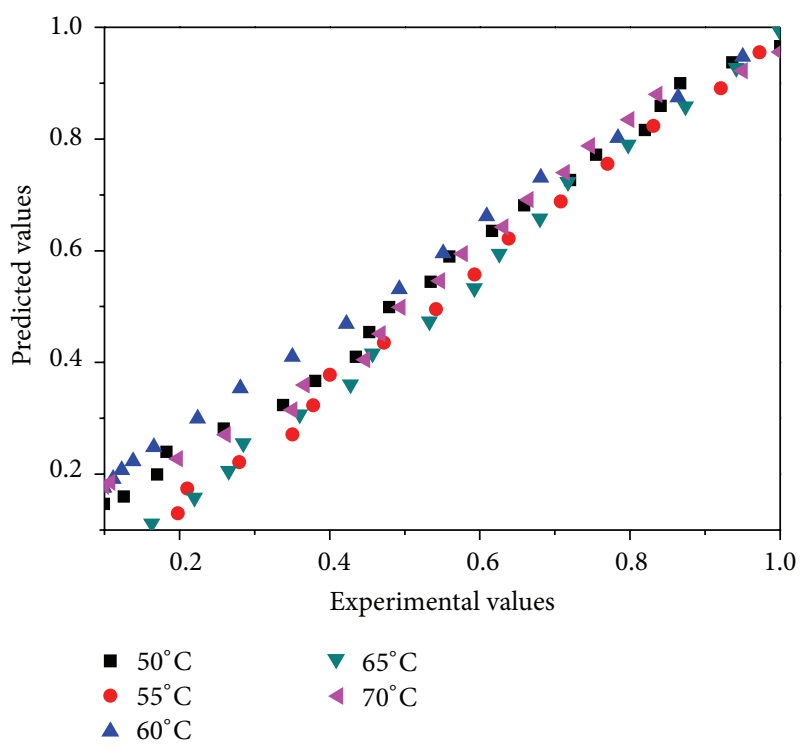

FIGURE 5: Comparison of experimental and predicted MR from the Weibull distribution model at different drying hot air temperatures.

Weibull distribution model were shown in Figures 5, 6 and 7, respectively. Obviously, there was a good consistency between the value of MR obtained from experiment and the prediction value based on Weibull distribution model. More specifically, the distribution of these data points was approximately in banded linear map with angle of $45^{\circ} \mathrm{C}$, which could be further demonstrated that Weibull distribution model was a good prediction for hawthorn slices drying characteristics of microwave coupled with hot air. The similar results had been reported by Shi et al. for yacon slices [35], Yi et al. [6] and Soysal et al. [41] for parsley, and so forth.

3.4. Estimation of Effective Moisture Diffusivities. During the falling rate drying period, the internal resistance governed the mass transfer and the moisture transfer during drying was controlled by internal diffusion. In this case, Fick's second law of diffusion could be used as an effective prediction. According to the drying time $t$ and the value of MR and InMR that calculated from the experiment data, the effective diffusion coefficients calculated by (6) and (7) obtained under various experimental conditions were shown in Table 5. As expected, when the drying conditions remained on a constant of power density $9 \mathrm{w} / \mathrm{g}$ and hot air velocity $2 \mathrm{~m} / \mathrm{s}$, and the temperature increases $\left(50 \sim 70^{\circ} \mathrm{C}\right)$, the effective diffusivity values decreased after increase with the increase of temperature. When the power density of $9 \mathrm{w} / \mathrm{g}$ and air temperature of $60^{\circ} \mathrm{C}$ kept constant, with increasing hot air velocity $(1 \sim 3 \mathrm{~m} / \mathrm{s})$, the effective moisture diffusion values first increased and then decreased. When the hot air temperature of $60^{\circ} \mathrm{C}$ and the hot air velocity of $2 \mathrm{~m} / \mathrm{s}$ remained constant, with the power density increases $(3 \sim 15 \mathrm{w} / \mathrm{g})$, the effective moisture diffusion values increased with power density increasing. It was consistent with the variation law of MR [30]. Under the experimental conditions, the effective moisture diffusion values varied from $1.16349 \times 10^{-7}$ to $3.77045 \times 10^{-7} \mathrm{~m}^{2} / \mathrm{s}$. Unal

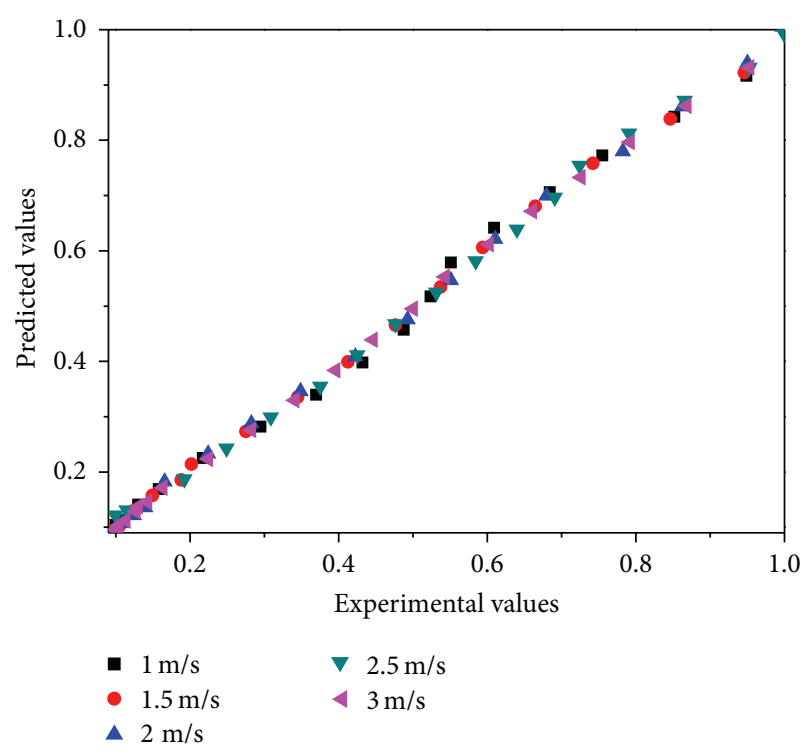

FIGURE 6: Comparison of experimental and predicted MR from the Weibull distribution model at different drying hot air velocity.

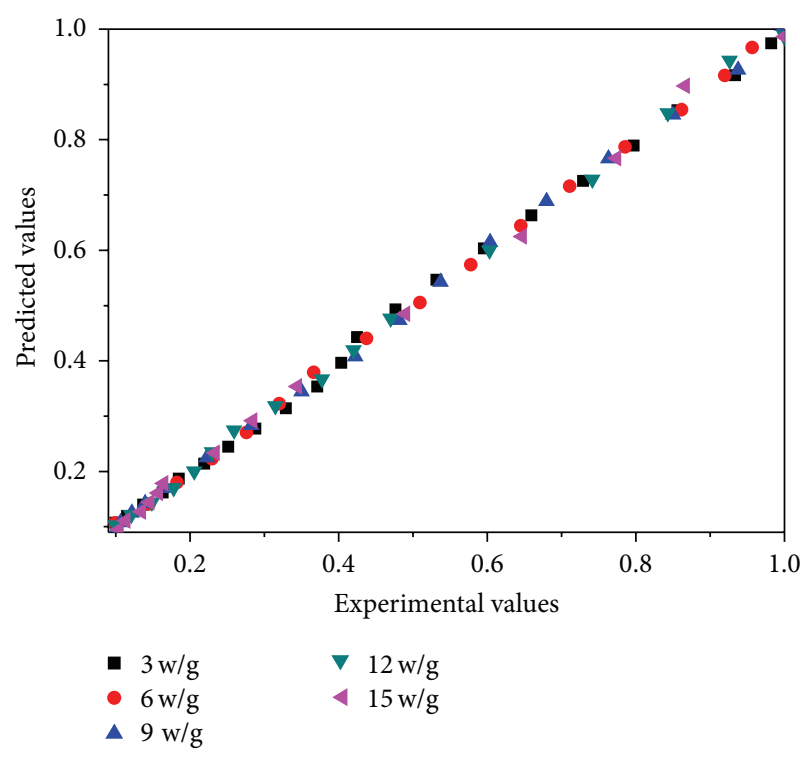

FIGURE 7: Comparison of experimental and predicted MR from the Weibull distribution model at different microwave power density.

and Sacilik [4] researched on hot air to dry hawthorn, the range of effective moisture diffusivity values obtained was $2.66 \times 10^{-10} \sim 5.70 \times 10^{-10} \mathrm{~m}^{2} / \mathrm{s}$, which was three orders of magnitude smaller than that of microwave coupled with hot air. The reason for so much difference was mainly due to the different type of hawthorn, drying method, drying conditions, physical or chemical pretreatment (physical or chemical pretreatment), geometry (i.e., thickness or radius), and moisture content (d. b.) [35]. 
TABLE 5: Effective moisture diffusivity values of hawthorn slices.

\begin{tabular}{lcccc}
\hline $\begin{array}{l}\text { Power } \\
\text { density } \\
(\mathrm{w} / \mathrm{g})\end{array}$ & $\begin{array}{c}\text { Hot air } \\
\text { velocity } \\
(\mathrm{m} / \mathrm{s})\end{array}$ & $\begin{array}{c}\text { Hot air } \\
\text { temperature } \\
\left({ }^{\circ} \mathrm{C}\right)\end{array}$ & Slope & Deff \\
\hline 9 & 2 & 50 & -0.07177 & $1.16349 \times 10^{-7}$ \\
9 & 2 & 55 & -0.08618 & $1.3971 \times 10^{-7}$ \\
9 & 2 & 60 & -0.12454 & $2.01897 \times 10^{-7}$ \\
9 & 2 & 65 & -0.09484 & $1.53749 \times 10^{-7}$ \\
9 & 2 & 70 & -0.07697 & $1.24779 \times 10^{-7}$ \\
9 & 1 & 60 & -0.11184 & $1.81308 \times 10^{-7}$ \\
9 & 1.5 & 60 & -0.12699 & $2.05868 \times 10^{-7}$ \\
9 & 2 & 60 & -0.12248 & $1.98557 \times 10^{-7}$ \\
9 & 2.5 & 60 & -0.09258 & $1.50085 \times 10^{-7}$ \\
9 & 3 & 60 & -0.10869 & $1.76202 \times 10^{-7}$ \\
3 & 2 & 60 & -0.08189 & $1.32755 \times 10^{-7}$ \\
6 & 2 & 60 & -0.09425 & $1.52792 \times 10^{-7}$ \\
9 & 2 & 60 & -0.12547 & $2.03404 \times 10^{-7}$ \\
12 & 2 & 60 & -0.16851 & $2.73178 \times 10^{-7}$ \\
15 & 2 & 60 & -0.23258 & $3.77045 \times 10^{-7}$ \\
\hline
\end{tabular}

\section{Conclusions}

In this paper, the effects of dry factor on moisture ratio and drying rate of microwave coupled with hot air drying were systematically studied and the reason for the drying curve trends was analyzed, under the drying conditions of hot air temperature being ranged from $50^{\circ} \mathrm{C}$ to $70^{\circ} \mathrm{C}$, microwave density being ranged from 3 to $15 \mathrm{w} / \mathrm{g}$, and hot air velocity being ranged from 1 to $3 \mathrm{~m} / \mathrm{s}$. In this study, it was found that the drying process occurred only in accelerating period and falling rate period and no significant constant rate drying period existed. The drying curves were fitted to 12 different drying mathematical models which were often used and it was found in this study that there were a maximum value of $R^{2}$ and a minimum value of $\chi^{2}$ and RMSE under the experimental conditions in Weibull distribution model. Therefore, the Weibull distribution model was found to be the most suitable for describing drying curves of hawthorn slices. It could be used to predict the characteristics of the hawthorn slices during a drying process at any time, particularly at hot air temperatures of $50-70^{\circ} \mathrm{C}$ and hot air velocities of $1-3 \mathrm{~m} / \mathrm{s}$ and microwave power densities of 3-15 w/g. The calculated effective diffusivities ranged from $1.16349 \times 10^{-7}$ to 3.77045 $\times 10^{-7} \mathrm{~m}^{2} / \mathrm{s}$. The variation of effective diffusion coefficient was consistent with that of drying moisture ration. Moreover, according to literature [4], the effective diffusivities of convective hot air drying ranged from $2.66 \times 10^{-10}$ to $5.7 \times 10^{-10} \mathrm{~m}^{2} / \mathrm{s}$ and the value of hawthorn effective diffusion coefficient of microwave coupled with hot air drying technology was three orders of magnitude larger than that of convective hot air drying technology, which indicates a higher drying rate of microwave coupled with hot air drying technology compared with convective hot air drying technology.

\section{Nomenclature}

$a, b, c: \quad$ Empirical constants in the drying models

$g, k_{0}, k, k_{1}$ : Empirical coefficients in the drying

$M_{t}: \quad$ Moisture content (d. b.) at $t$,

$\mathrm{kg}_{\text {water }} / \mathrm{kg}_{\text {dry solids }}$

$M_{e}: \quad$ Equilibrium moisture content (d. b.),

$\begin{array}{ll}M_{0}: & \mathrm{kg}_{\text {water }} / \mathrm{kg}_{\text {dry solids }} \\ & \text { Initial moisture content (d. b.), }\end{array}$

$\mathrm{kg}_{\text {water }} / \mathrm{kg}_{\text {dry solids }}$

MR: Dimensionless moisture ratio

$\mathrm{MR}_{\text {exp }}$ : Experimental dimensionless moisture ratio

$\mathrm{MR}_{\mathrm{pre}}$ : Predicted dimensionless moisture ratio

$N: \quad$ Number of observations

$\chi^{2}: \quad$ Chi-square

$R^{2}: \quad$ Coefficient of determination

RMSE: $\quad$ Root mean square error

$j: \quad$ Number of drying constants

$t: \quad$ Drying time, min

T: $\quad$ Temperature, ${ }^{\circ} \mathrm{C}$

v: $\quad$ Velocity, $\mathrm{m} / \mathrm{s}$

d. b.: $\quad$ Dry basis, $\mathrm{kg}_{\text {water }} / \mathrm{kg}_{\text {dry solids }}$

DR: $\quad$ Drying rate, $\mathrm{kg}_{\text {water }} / \mathrm{kg}_{\text {dry solids }}$

$D_{\text {eff: }} \quad$ Effective moisture diffusivity coefficient, $\mathrm{m}^{2} / \mathrm{s}$

$L: \quad$ Half-thickness of the slab, $m$

w. b.: $\quad$ Wet basis, $\mathrm{kg}_{\text {water }} / \mathrm{kg}_{\text {mass }}$.

\section{Conflict of Interests}

The authors declare that there is no conflict of interests regarding the publication of this paper.

\section{Acknowledgments}

This work was funded by the National Natural Science Foundation of China (no. 51175223). It was also financially supported by the key disciplines of the agricultural mechanization engineering of Heilongjiang Bayi Agricultural University.

\section{References}

[1] P. Liu, B. Yang, and H. Kallio, "Characterization of phenolic compounds in Chinese hawthorn (Crataegus pinnatifida Bge. var. major) fruit by high performance liquid chromatographyelectrospray ionization mass spectrometry," Food Chemistry, vol. 121, no. 4, pp. 1188-1197, 2010.

[2] G. F. Yang, Y. L. Wang, and R. Q. Li, "Development and application of Hawthorn," Forest By-Product and Speciality in China, no. 2, pp. 98-101, 2010.

[3] T. Liu, Y. Cao, and M. Zhao, "Extraction optimization, purification and antioxidant activity of procyanidins from hawthorn (C. pinnatifida Bge. var. major) fruits," Food Chemistry, vol. 119, no. 4, pp. 1656-1662, 2010.

[4] H. G. Unal and K. Sacilik, "Drying characteristics of hawthorn fruits in a convective hot-air dryer," Journal of Food Processing and Preservation, vol. 35, no. 2, pp. 272-279, 2011. 
[5] R. K. Goyal, A. R. P. Kingsly, M. R. Manikantan, and S. M. Ilyas, "Mathematical modelling of thin layer drying kinetics of plum in a tunnel dryer," Journal of Food Engineering, vol. 79, no. 1, pp. 176-180, 2007.

[6] X.-K. Yi, W.-F. Wu, Y.-Q. Zhang, J.-X. Li, and H.-P. Luo, “Thinlayer drying characteristics and modeling of Chinese jujubes," Mathematical Problems in Engineering, vol. 2012, Article ID 386214, 18 pages, 2012.

[7] H. O. Menges and C. Ertekin, "Mathematical modeling of thin layer drying of Golden apples," Journal of Food Engineering, vol. 77, no. 1, pp. 119-125, 2006.

[8] V. R. Sagar and P. S. Kumar, "Recent advances in drying and dehydration of fruits and vegetables: a review," Journal of Food Science and Technology, vol. 47, no. 1, pp. 15-26, 2010.

[9] S. Sun and Z. W. Cui, "Mathematical modeling of microwave assisted air drying of cylindrical carrot samples," Science and Technology of Food Industry, vol. 34, no. 12, pp. 161-172, 2013.

[10] Y. Z. Lv, Z. H. Ling, G. Liu, and L. Ying, "Study on effect of vitamin $C$ stability of hawthorn by different drying methods in the drying process," Farm Products Processing, no. 6, pp. 70-71, 2011.

[11] M. Zhang, J. Tang, A. S. Mujumdar, and S. Wang, "Trends in microwave-related drying of fruits and vegetables," Trends in Food Science \& Technology, vol. 17, no. 10, pp. 524-534, 2006.

[12] A. Reyes, S. Cerón, R. Zúñiga, and P. Moyano, "A comparative study of microwave-assisted air drying of potato slices," Biosystems Engineering, vol. 98, no. 3, pp. 310-318, 2007.

[13] A. Figiel, "Drying kinetics and quality of beetroots dehydrated by combination of convective and vacuum-microwave methods," Journal of Food Engineering, vol. 98, no. 4, pp. 461-470, 2010.

[14] J. Bondaruk, M. Markowski, and W. Błaszczak, "Effect of drying conditions on the quality of vacuum-microwave dried potato cubes," Journal of Food Engineering, vol. 81, no. 2, pp. 306-312, 2007.

[15] A. Gowen, N. Abu-Ghannam, J. Frias, and J. Oliveira, "Optimisation of dehydration and rehydration properties of cooked chickpeas (Cicer arietinum L.) undergoing microwave-hot air combination drying," Trends in Food Science and Technology, vol. 17 , no. 4 , pp. $177-183,2006$.

[16] A. Andrés, P. Fito, A. Heredia, and E. M. Rosa, "Combined drying technologies for development of high-quality shelfstable mango products," Drying Technology, vol. 25, no. 11, pp. 1857-1866, 2007.

[17] A. A. Gowen, N. Abu-Ghannam, J. Frias, and J. Oliveira, "Modeling dehydration and rehydration of cooked soybeans subjected to combined microwave-hot-air drying," Innovative Food Science and Emerging Technologies, vol. 9, no. 1, pp. 129137, 2008.

[18] R. Vadivambal and D. S. Jayas, "Changes in quality of microwave-treated agricultural products-a review," Biosystems Engineering, vol. 98, no. 1, pp. 1-16, 2007.

[19] H. O. Menges and C. Ertekin, "Thin layer drying model for treated and untreated Stanley plums," Energy Conversion and Management, vol. 47, no. 15-16, pp. 2337-2348, 2006.

[20] R. P. F. Guiné, M. J. Barroca, F. J. Gonçalves, M. Alves, S. Oliveira, and M. Mendes, "Artificial neural network modelling of the antioxidant activity and phenolic compounds of bananas submitted to different drying treatments," Food Chemistry, vol. 168, pp. 454-459, 2015.
[21] T. K. Gachovska, A. A. Adedeji, M. Ngadi, and G. V. S Raghavan, "Drying characteristics of pulsed electric fieldtreated carrot," Drying Technology, vol. 26, no. 10, pp. 1244-1250, 2008.

[22] S. J. Babalis, E. Papanicolaou, N. Kyriakis, and V. G. Belessiotis, "Evaluation of thin-layer drying models for describing drying kinetics of figs (Ficus carica)," Journal of Food Engineering, vol. 75, no. 2, pp. 205-214, 2006.

[23] S. Janjai, M. Precoppe, N. Lamlert et al., "Thin-layer drying of litchi (Litchi chinensis Sonn.)," Food and Bioproducts Processing, vol. 89, no. 3, pp. 194-201, 2011.

[24] S. D. F. Mihindukulasuriya and H. P. W. Jayasuriya, "Mathematical modeling of drying characteristics of chilli in hot air oven and fluidized bed dryers," Agricultural Engineering International: CIGR Journal, vol. 15, no. 1, pp. 154-166, 2013.

[25] I. Alibas, "Microwave, vacuum, and air drying characteristics of collard leaves," Drying Technology, vol. 27, no. 11, pp. 1266-1273, 2009.

[26] D. Zhao, C. Zhao, H. Tao, K. An, S. Ding, and Z. Wang, "The effect of osmosis pretreatment on hot-air drying and microwave drying characteristics of chili (Capsicum annuum L.) flesh," International Journal of Food Science and Technology, vol. 48, no. 8, pp. 1589-1595, 2013.

[27] S. Bai-Ngew, N. Therdthai, and P. Dhamvithee, "Characterization of microwave vacuum-dried durian chips," Journal of Food Engineering, vol. 104, no. 1, pp. 114-122, 2011.

[28] N. Nimmanpipug, N. Therdthai, and P. Dhamvithee, "Characterisation of osmotically dehydrated papaya with further hot air drying and microwave vacuum drying," International Journal of Food Science \& Technology, vol. 48, no. 6, pp. 1193-1200, 2013.

[29] E. E. Abano, H. Ma, and W. Qu, "Influence of combined microwave-vacuum drying on drying kinetics and quality of dried tomato slices," Journal of Food Quality, vol. 35, no. 3, pp. 159-168, 2012.

[30] J. Varith, P. Dijkanarukkul, A. Achariyaviriya, and S. Achariyaviriya, "Combined microwave-hot air drying of peeled longan," Journal of Food Engineering, vol. 81, no. 2, pp. 459-468, 2007.

[31] I. Alibas, "Microwave, air and combined microwave-air-drying parameters of pumpkin slices," LWT: Food Science and Technology, vol. 40, no. 8, pp. 1445-1451, 2007.

[32] T. Orikasa, L. Wu, T. Shiina, and A. Tagawa, "Drying characteristics of kiwifruit during hot air drying," Journal of Food Engineering, vol. 85, no. 2, pp. 303-308, 2008.

[33] A. Motavali, G. H. Najafi, S. Abbasi, S. Minaei, and A. Ghaderi, "Microwave-vacuum drying of sour cherry: comparison of mathematical models and artificial neural networks," Journal of Food Science and Technology, vol. 50, no. 4, pp. 714-722, 2013.

[34] I. Doymaz, "Convective air drying characteristics of thin layer carrots," Journal of Food Engineering, vol. 61, no. 3, pp. 359-364, 2004.

[35] Q. Shi, Y. Zheng, and Y. Zhao, "Mathematical modeling on thin-layer heat pump drying of yacon (Smallanthus sonchifolius) slices," Energy Conversion and Management, vol. 71, pp. 208-216, 2013.

[36] A. Kaya and O. Aydin, "An experimental study on drying kinetics of some herbal leaves," Energy Conversion and Management, vol. 50, no. 1, pp. 118-124, 2009.

[37] A. Sarimeseli, "Microwave drying characteristics of coriander (Coriandrum sativum L.) leaves," Energy Conversion and Management, vol. 52, no. 2, pp. 1449-1453, 2011. 
[38] E. Akpinar, A. Midilli, and Y. Bicer, "Single layer drying behaviour of potato slices in a convective cyclone dryer and mathematical modeling," Energy Conversion and Management, vol. 44, no. 10, pp. 1689-1705, 2003.

[39] E. K. Akpinar, Y. Bicer, and A. Midilli, "Modeling and experimental study on drying of apple slices in a convective cyclone dryer," Journal of Food Process Engineering, vol. 26, no. 6, pp. 515-541, 2003.

[40] T. Funebo and T. Ohlsson, "Dielectric properties of fruits and vegetables as a function of temperature and moisture content," Journal of Microwave Power and Electromagnetic Energy, vol. 34, no. 1, pp. 42-54, 1999.

[41] Y. Soysal, S. Öztekin, and Ö. Eren, "Microwave drying of parsley: modelling, kinetics, and energy aspects," Biosystems Engineering, vol. 93, no. 4, pp. 403-413, 2006.

[42] P. C. Corrêa, F. M. Botelho, G. H. H. Oliveira, A. L. D. Goneli, O. Resende, and S. de Carvalho Campos, "Mathematical modeling of the drying process of corn ears," Acta ScientiarumAgronomy, vol. 33, no. 4, pp. 575-581, 2011.

[43] S. P. S. M. Hendersonand, "Grain drying theory.1.Temperature effect on drying coefficient," Journal of Agricultural Engineering Research, vol. 6, pp. 169-174, 1961.

[44] S. M. Henderson, "Progress in developing the thin-layer drying equation," Transactions of the American Society of Agricultural Engineers, vol. 17, no. 6, pp. 1167-1172, 1974.

[45] Y. I. Sharaf-Eldeen, J. L. Blaisdell, and M. Y. Hamdy, "A model for ear corn drying," Transactions of the American Society of Agricultural Engineers, vol. 23, no. 5, pp. 1261-1271, 1980.

[46] L. R. Verma, R. A. Bucklin, J. B. Endan, and F. T. Wratten, "Effects of drying air parameters on rice drying models," Transactions of the American Society of Agricultural Engineers, vol. 28, no. 1, pp. 296-301, 1985.

[47] M. Özdemir and Y. O. Devres, "Thin layer drying characteristics of hazelnuts during roasting," Journal of Food Engineering, vol. 42, no. 4, pp. 225-233, 1999.

[48] C. Chen and P.-C. Wu, "Thin-layer drying model for rough rice with high moisture content," Journal of Agricultural Engineering Research, vol. 80, no. 1, pp. 45-52, 2001.

[49] O. Yaldýz and C. Ertekýn, "Thin layer solar drying of some vegetables," Drying Technology, vol. 19, no. 3-4, pp. 583-597, 2001.

[50] I. Doymaz, "Mathematical modeling of drying of tomato slices using infrared radiation," Journal of Food Processing and Preservation, vol. 38, no. 1, pp. 389-396, 2014.

[51] W. Weibull, "A statistical distribution of wide applicability," Journal of Applied Mechanics, vol. 18, pp. 293-297, 1951. 


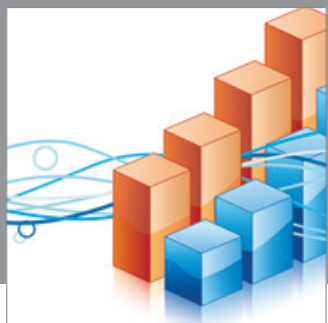

Advances in

Operations Research

mansans

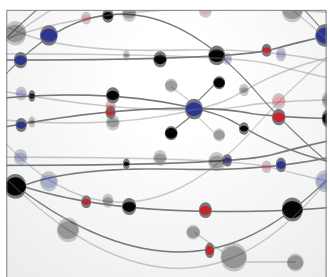

The Scientific World Journal
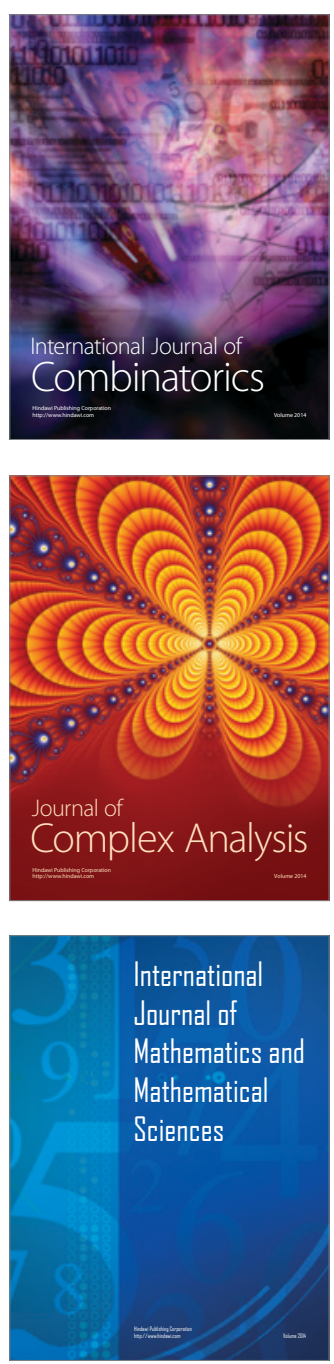
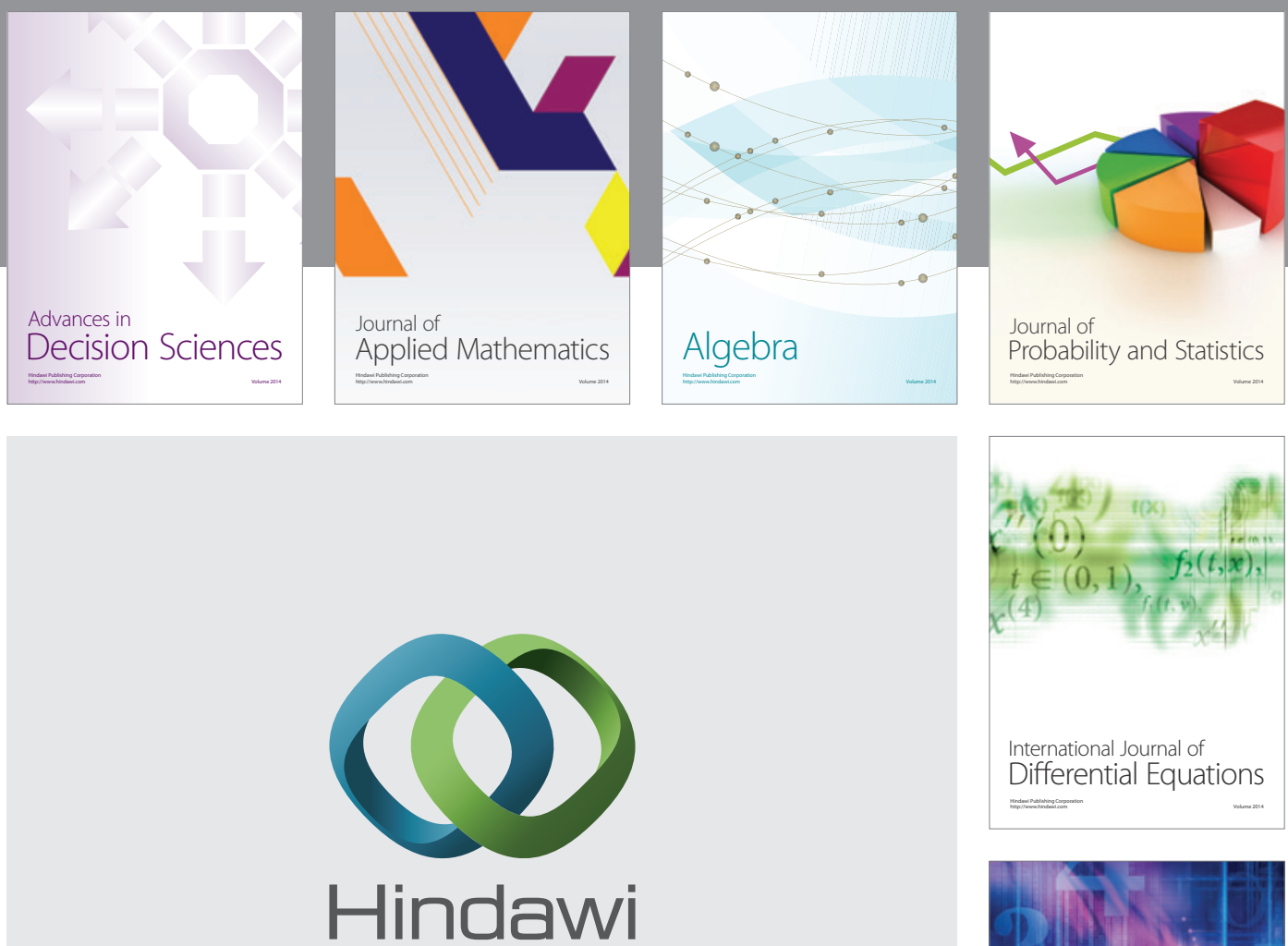

Submit your manuscripts at http://www.hindawi.com
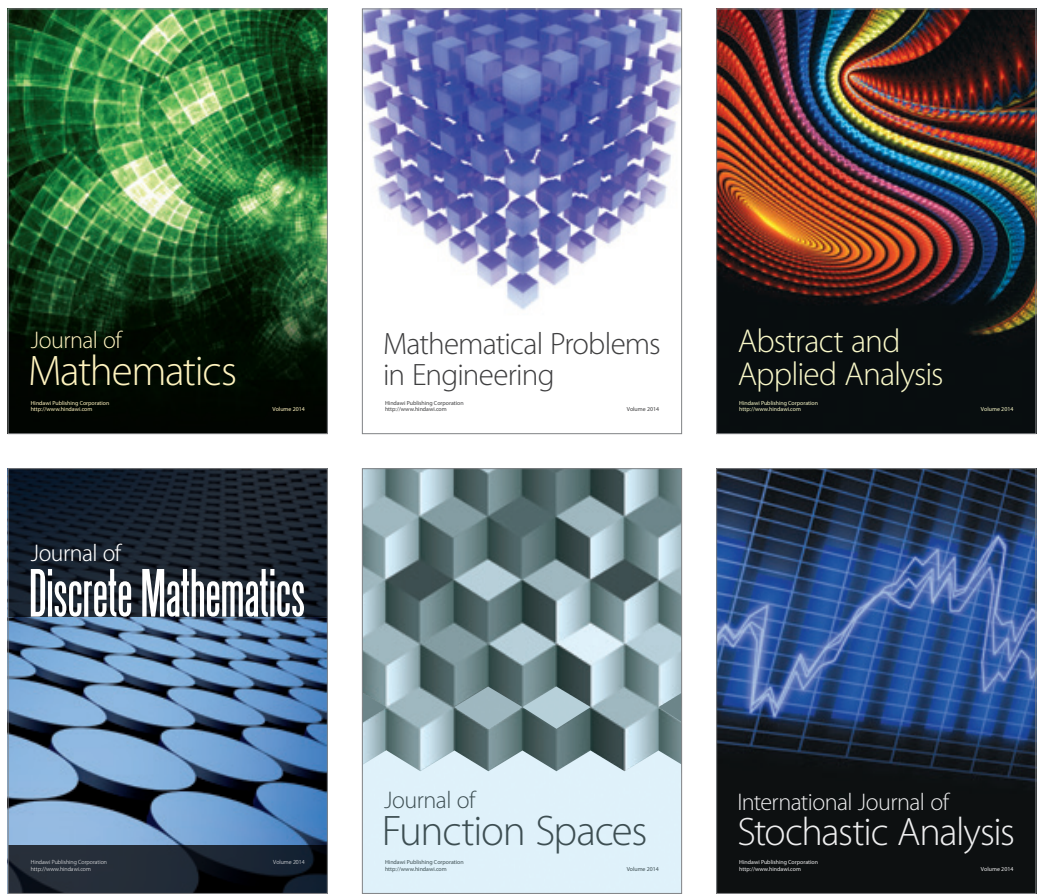

Journal of

Function Spaces

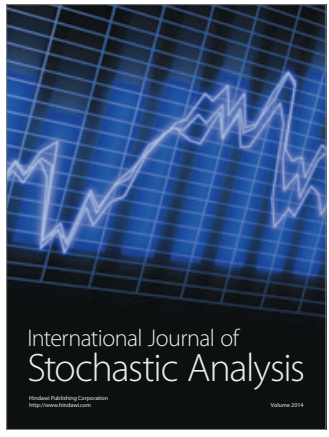

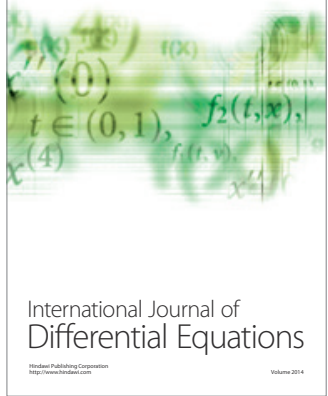
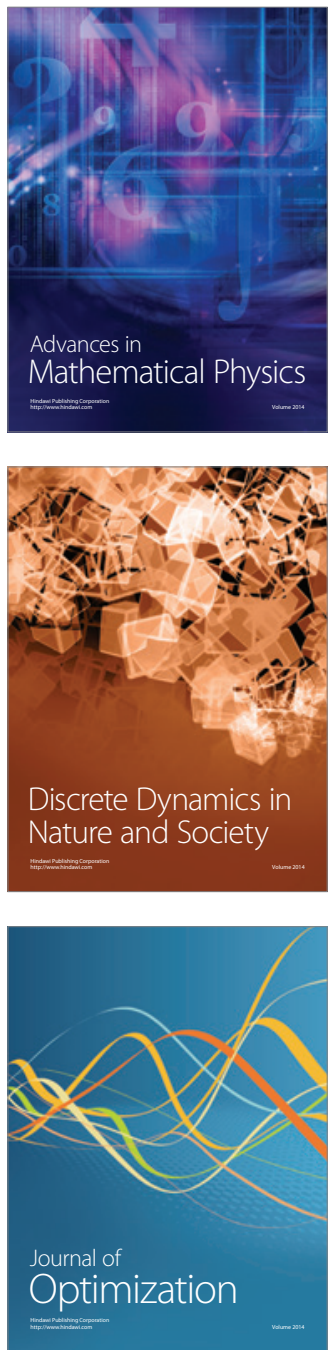